\title{
Erratum
}

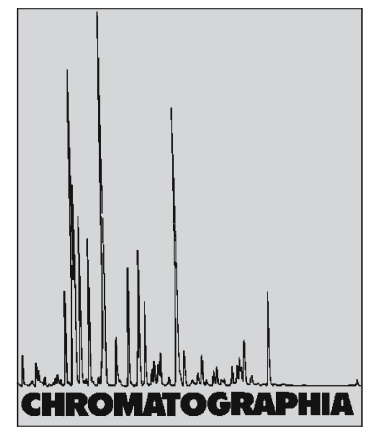

2008, 67, 499

\section{Validation of a Stability-Indicating LC Method for Assay of Ezetimibe in Tablets and for Determination of Content Uniformity}

Ashish S. Doshi ${ }^{\varpi}$, Pankaj K. Kachhadia, Hitendra S. Joshi

Department of Chemistry, Saurashtra University, Rajkot 360 005, India; E-Mail: eashish2@rediffmail.com

Erratum to: Chromatographia (2008) 67:137-142

DOI 10.1365/s10337-007-0470-9

Unfortunately, the last author's name (H. S. Joshi) was spelled incorrectly. The correct name is Hitendra S. Joshi. 